\title{
Attitudes towards Risk and Inequality: A Questionnaire-Experimental Approach
}

by

\section{Yoram Amiel}

Ruppin Institute, Israel

and

\section{Frank Cowell}

London School of Economics

Discussion Paper

No. DARP 56

June 2000
Distributional Analysis Research Programme The Toyota Centre Suntory and Toyota International Centres for Economics and Related Disciplines London School of Economics Houghton Street London WC2A 2AE 


\section{Distributional Analysis Research Programme}

The Distributional A nalysis Research Programme was established in 1993 with funding from the Economic and Social Research Council. It is located within the Suntory and Toyota International Centres for Economics and Related Disciplines (STICERD) at the London School of Economics and Political Science. The programme is directed by Frank Cowell. The Discussion Paper series is available free of charge and most papers are downloadablefrom the website. To subscribe to the DA RP paper series, or for further information on the work of the Programme, please contact our Research Secretary, Sue Coles on:
Telephone: $\quad$ UK +2079556678
Fax:
UK+20 79556951
Email:
s.coles@se.ac.uk
Web site:
http:/ / sticerd.Ise.ac.uk/ DARP

(c) Authors: Yoram Amiel and Frank Cowell

All rights reserved. Short sections of text, not to exceed two paragraphs, may be quoted without explicit permission provided that full credit, including $\odot$ notice, is given to the source. 


\begin{abstract}
Orderings of income distributions in terms of inequality should be closely related to orderings in terms of risk. Using a novel multi-country questionnaire experiment we examine the basis for this claim in terms of respondents' distributional perceptions. We show that in terms of both inequality and risk individuals consistently reject one of the standard axioms of distributional comparison. Moreover there are significant differences in the "maps" of inequality and risk comparisons. Rejection of the orthodox approach is less likely to occur when distributional comparisons involve the extremes of the distributions. We show that certain key background variables are overwhelmingly important in predisposing individuals toward acceptance or rejection of the orthodox basis for distributional comparisons.

This paper forms part of the research programme of the TMR network Living Standards, Inequality and Taxation [Contract No. ERBFMRXCT 980248] of the European Communities whose financial support is gratefully acknowleged.
\end{abstract}

- JEL Classification: C13, D63

- Keywords: inequality, risk, experiment, transfer principle. 


\section{Introduction}

Attitudes to inequality and risk can be interpreted in a number of ways. A standard approach is to think in terms of strength of inequality aversion or risk aversion. and there are several studies which examine these questions from the standpoint of economic orthodoxy in these two fields, and some which investigate risk and inequality jointly within the standard framework ${ }^{1}$. However, in this paper we examine a deeper question that addresses the basis for statements about inequality or risk comparisons without incorporating a priori the key assumptions that impose structure on inequality indices, measures of risk or other distributional criteria. This is accomplished by use of a questionnaire-experimental study that permits one to investigate the way in which individuals' perceptions of income-distribution comparisons conform to, or depart from, the orthodox analytical framework.

Previous studies have analysed the underlying structure of attitudes towards risk and inequality separately (Amiel and Cowell 1999a,1999b; Amiel et al. 2000). However, in this case we are able to examine the structure of both types of comparison simultaneously by means of a device explained in Section 2. We analyse questionnaire responses of over 1100 students from seven countries in a joint inequality-and-risk questionnaire experiment.

The paper is arranged as follows. Sections 2 and 3 describe the experiment and resulting data set. Section 4 looks at all the responses to the numerical questions jointly, and Section 5 studies the variation in responses for specific numerical questions dealing with different types of equalising income transfers. Section 6 examines the implications of responses to the verbal part of the questionnaire. Section 7 concludes.

\section{The Experiment}

During 1998/99 a questionnaire experiment was carried out on twelve samples of undergraduate students from seven countries. The majority were economics students of some sort - others came from disciplines such as politics and law. The questionnaire was organised as follows. During regular class or lecture time the teacher found a slot to distribute two sets of questionnaires to the students. Each student received just one questionnaire and completed it under the supervision of the class teacher or lecturer in about 10 or 15 minutes. $^{2}$

\footnotetext{
${ }^{1}$ On the first see Amiel and Cowell (2000) for an overview. On the second see, for example the experimental approach of Kroll and Davidovitz (1999).

${ }^{2}$ In practice there was one exception to this noted in section 3 below.
} 
The reason for there being two sets of questionnaires was that we wished to obtain simultaneously two samples from the same population, one for each of the two issues, inequality and risk. The two documents required for the joint study were deliberately designed to be very similar - so that, at a glance, each respondent's questionnaire would appear to be the same as his neighbour's - see Appendix A.2. Students were simply told that they were to complete a "questionnaire on income distribution", and were not informed that there were actually two separate versions of the questionnaire study. The questionnaires consisted of three parts:

1. First respondents were asked to rank six pairs of income vectors (A and B) in terms of inequality or risk. This was motivated by a brief story about a country called "Alfaland": the five components of each vector represented incomes in the five regions of Alfaland; in each of the six questions each (A,B)-pair of vectors was supposed to represent the outcomes of two policies; in the risk context respondents were invited to suppose that a newcomer to Alfaland would be assigned at random to any one of the five regions, and that risk should be judged from the standpoint of such a newcomer. For each question, B was obtained from A by an equalising income transfer from a rich to a poor region without reversing the ordering of the two regions involved in the transfers. As we have seen, according to the Principle of Transfers, an equalising income transfer reduces inequality. Therefore, the Principle of Transfers would imply that $\mathrm{A}$ is more unequal (riskier) than $\mathrm{B}$ in all six numerical questions.

2. Respondents were then invited to look at the issue of the transfer principle (mean-preserving spreads) in terms of a simple extension of the story about Alfaland; this time an exclusively verbal approach was used for both inequality and risk versions. The details of this part of the questionnaire are discussed further in Section 6 below.

3. Finally respondents were asked for details about themselves, their backgrounds and their attitudes, although the questionnaire was conducted anonymously: the details of these questions are presented in the Appendix.

\section{Data}

Table 1 gives a summary of the number of students by country. The data set comprises students from seven countries (Argentina, Australia, Belgium, 


\begin{tabular}{lrrrrrr}
\hline \hline & \multicolumn{3}{c}{ Number } & \multicolumn{3}{c}{ Percentage } \\
& Total & Inequality & Risk & Total & Inequality & Risk \\
\cline { 2 - 7 } Argentina & 74 & 38 & 36 & 6 & 6 & 6 \\
Australia & 124 & 62 & 62 & 11 & 11 & 11 \\
Belgium & 137 & 87 & 50 & 12 & 15 & 9 \\
Germany & 264 & 126 & 138 & 23 & 21 & 24 \\
Israel & 180 & 93 & 87 & 16 & 16 & 15 \\
Sweden & 63 & 31 & 32 & 5 & 5 & 6 \\
UK & 311 & 150 & 161 & 27 & 26 & 28 \\
All countries & 1153 & 587 & 566 & 100 & 100 & 100 \\
\hline \hline
\end{tabular}

Table 1: Students by Country

Germany, Israel, Sweden, and the UK). A roughly equal number of students responded to the inequality and risk questionnaires (52\% versus $48 \%$ ). Students from Australia responded to both inequality and risk questionnaires. The results presented here include the Australian responses, but excluding them does not affect the main findings.

The students provided information about basic personal characteristics see the Appendix for the complete list. The characteristics for the inequality and risk subsamples are very similar, as shown in Table $2 .{ }^{3}$ With the exception of income in 2010, a $t$-test rejects the null hypothesis of equal means across inequality and risk samples for all characteristics at standard significance levels. Differences in the responses between risk and inequality are unlikely to be driven by systematic variation in the characteristics of the two subsamples.

Table 3 compares distinguishes between male and female subgroups. The $t$-statistics indicate some differences between the two groups, in particular for the inequality subsample. Male students tend to be older, to have more work experience, to be more conservative, and to have a higher estimated income in 2010. It will be important to control for these covariates when we want to isolate the influence of gender on attitudes towards risk and inequality.

\footnotetext{
${ }^{3}$ Students were asked to rate their political view, family income 1990, and family income 2010 on a scale from one to seven. Income Change 2010 is defined as the difference between Income 2010 and Income 1990. Employment refers to any work history before university. Economic subject comprises economics, econometrics, economic history, mathematical economics, and development economics. The main results of the paper remain unaffected if we use a wider definition, including in addition MBAs and the subjects accounting and finance, management science, and business studies.
} 


\begin{tabular}{llllll}
\hline \hline & \multicolumn{2}{c}{ Inequality } & Risk & \multicolumn{2}{c}{ P-value* } \\
& Mean & SD & Mean & SD & \\
\cline { 2 - 6 } Gender & 0.63 & 0.48 & 0.61 & 0.49 & 66 \\
Age & 22.95 & 4.44 & 23.21 & 4.01 & 32 \\
Employment & 0.40 & 0.49 & 0.44 & 0.50 & 24 \\
Political Opinion & 4.03 & 1.05 & 3.97 & 1.05 & 39 \\
Income 1990 & 4.32 & 1.01 & 4.25 & 1.10 & 33 \\
Income 2010 & 5.04 & 0.91 & 4.91 & 1.00 & 2 \\
Economic Subject (core) & 0.29 & 0.45 & 0.30 & 0.46 & 64 \\
Economic Subject (broader) & 0.75 & 0.43 & 0.72 & 0.45 & 24 \\
\hline
\end{tabular}

*Equality in means across risk and inequality subgroup.

Table 2: Personal Characteristics of Students

\begin{tabular}{lccccc}
\hline \hline & \multicolumn{4}{c}{ Male } & \multicolumn{2}{c}{ Female } & P-value* \\
& Mean & $S D$ & Mean & $S D$ & \\
\cline { 2 - 6 } RISK & & & & & \\
Age & 23.77 & 4.52 & 22.27 & 2.81 & 0 \\
Employment & 0.48 & 0.50 & 0.36 & 0.48 & 0 \\
Political Opinion & 4.04 & 1.06 & 3.88 & 1.03 & 8 \\
Income 1990 & 4.27 & 1.20 & 4.23 & 0.94 & 66 \\
Income Change 2010 & 0.73 & 1.42 & 0.48 & 1.23 & 0 \\
Economic Subject (c) & 0.33 & 0.47 & 0.27 & 0.44 & 10 \\
\cline { 2 - 6 } INEQUALITY & & & & \\
Age & 23.40 & 4.99 & 22.14 & 3.26 & 0 \\
Employment & 0.45 & 0.50 & 0.32 & 0.47 & 0 \\
Political Opinion & 4.10 & 1.10 & 3.90 & 0.96 & 2 \\
Income 1990 & 4.39 & 0.98 & 4.18 & 1.05 & 2 \\
Income Change 2010 & 0.77 & 1.15 & 0.60 & 1.31 & 11 \\
Economic Subject (c) & 0.30 & 0.46 & 0.28 & 0.45 & 75 \\
\hline *Equality in means across risk and inequality subgroup. & \\
\hline \hline
\end{tabular}

Table 3: Personal Characteristics of Male and Female Students 


\begin{tabular}{lcc}
\hline \hline & \multicolumn{1}{c}{ Inequality } & Risk \\
\cline { 2 - 3 } Equalising & Transfer Reduces & Inequality?* \\
Total & 59 & 61 \\
Male & 61 & 67 \\
Female & 57 & 53 \\
Consistency & with Transfer & Principle?** \\
Total & 17 & 23 \\
Male & 21 & 31 \\
Female & 10 & 11 \\
\hline *Proportion of answer A. & \\
**Proportion of answer A in all six questions \\
\hline \hline
\end{tabular}

Table 4: Percentage Shares of Response A

\section{Numerical responses and the Principle of Transfers}

\subsection{Descriptive results}

The issues that one can address with part 1 of the questionnaire concern inferences drawn from respondents' choices on each pair of vectors or on the pattern of responses over all six numerical problems: do they view a particular equalising income transfer as inequality and risk reducing? Are their responses jointly consistent with the Principle of Transfers? Table 4 shows simple summary statistics of the responses. ${ }^{4}$ For both inequality and risk, about $60 \%$ of the responses view an equalising transfer as inequality/risk reducing. However, no more than about one fifth of the students ticked response A for all six questions. The consistency with the Principle of Transfers is higher for risk (23\%) than for inequality (17\%).

Male and female subjects differ markedly in their responses in both risk and inequality subsamples: women are more likely to answer A if the question is in the inequality context whereas men are more likely to do so if it is in the context of risk. The differences are stronger for risk attitudes: male students are $25 \%$ more likely to check answer A, and almost three times more consistent with the Principle of Transfers than female students.

\footnotetext{
${ }^{4}$ Throughout the analysis we lump the responses "A and B have same level of inequality/risk" and "B has higher inequality/risk than A" into one category. Distinguishing between these responses does not affect the qualitative results of the analysis.
} 


\subsection{Regression Analysis}

The question immediately arises whether gender remains an important determinant of heterodox responses once one controls for other personal characteristics. To address this we use a standard probit regressions of the form

$$
\operatorname{Pr}(\text { Response Pattern })=\Phi\left(b_{1} y_{1}+b_{2} y_{2}+\ldots+b_{n} y_{n}\right)
$$

where $y_{j}$ is a measure of personal or background characteristic $j$ and $\left(b_{1}, \ldots, b_{n}\right)$ is a vector of coefficients. Given that there were $m$ separate numerical questions (where $m=6$ in our case) in which only the answer $A$ is consistent with economic orthodoxy there are two main interpretations of "Response Pattern" in (1) that of particular interest to us:

1. $m$ separate responses (each of which could be $A$ or $B$ or $A \& B$ ). This gives us in principle $m N$ observations.

2. a single response pattern in which only $A A \ldots A$ is consistent with economic orthodoxy. Clearly there are just $N$ observations here

Table 5 and Table 6 display the results of these two interpretations. Again, we look at both responses across all questions, and consistency with the Principle of Transfers. For the regression in Table 5 (interpretation 1 above), the response $A$ was indexed as unity, and as zero otherwise. For Table 6 (interpretation 2), the response $A$ in all six questions together was indexed as unity, and any other response as zero. The dependent variables are age, political opinion, income rank in 1990, the expected change in the income rank from 1990 to 2010, and dummies for gender (1 for male), previous work history, economic subject and country origin: the Appendix discusses the specification of these variables further.

On either interpretation the story is extremely clear. There are four main features to it:

- First, studying an economic subject is significant in both specifications and is highly significant if one takes each question separately. ${ }^{5}$ This is to be expected from previous studies (Amiel and Cowell 1992) and accords, perhaps, with intuition: on the whole, those studying economics are more likely to make distributional comparisons in line with economic orthodoxy.

\footnotetext{
${ }^{5}$ It is significant at the $10 \%$ level in Table 6 This result is robust under changes in the definition of "economic subject" - see the Appendix.
} 


\begin{tabular}{|c|c|c|c|c|c|}
\hline \multirow[t]{2}{*}{ Variable } & \multicolumn{2}{|c|}{ Inequality } & \multicolumn{2}{|c|}{ Risk } & \multirow[t]{2}{*}{$\overline{\mathrm{P} \text {-value** }}$} \\
\hline & Coef* & $P>|z|$ & Coef* & $P>|z|$ & \\
\hline Gender & 0.05 & 1 & 0.13 & 0 & 0 \\
\hline Age & 0.00 & 63 & 0.00 & 50 & 37 \\
\hline Employment & 0.02 & 35 & 0.00 & 94 & 55 \\
\hline Political opinion & 0.00 & 52 & -0.01 & 29 & 75 \\
\hline Income 1990 & 0.00 & 75 & 0.01 & 40 & 72 \\
\hline Income Change 2010 & 0.01 & 19 & 0.00 & 85 & 40 \\
\hline Economic Subject & 0.10 & 0 & 0.15 & 0 & 16 \\
\hline
\end{tabular}

Explanatory variables include dummy variables for countries.

Number of observations 6767

*Marginal effects. ${ }^{* *}$ Equality of coefficients across subgroups.

Table 5: Probit Regression of Response A

- Second, gender has a similar impact. Male students view more often an equalising transfer as inequality-reducing risk-reducing (taking each of the six questions separately) and are more consistent with the Principle of Transfers (all questions together). This is striking because, in the nature of the specification of the model, it is a factor separate from that of economic subject. The phenomenon cannot be explained away by the fact that more males choose to pursue economic subjects than females.

- Third, the coefficients on gender and economic subject are larger for risk than inequality.

- Finally, the other personal characteristics are on the whole not significant.

\section{Numerical Responses: variation by Type of Income Transfer}

\subsection{Descriptive Analysis}

Up to this point, we have considered all questions jointly, ignoring any variation in responses amongst questions. Table 7 shows the percentages of response $\mathrm{A}$ for each of the six questions. It compares the responses for inequality and risk for the entire sample and across the male and female subgroups. 


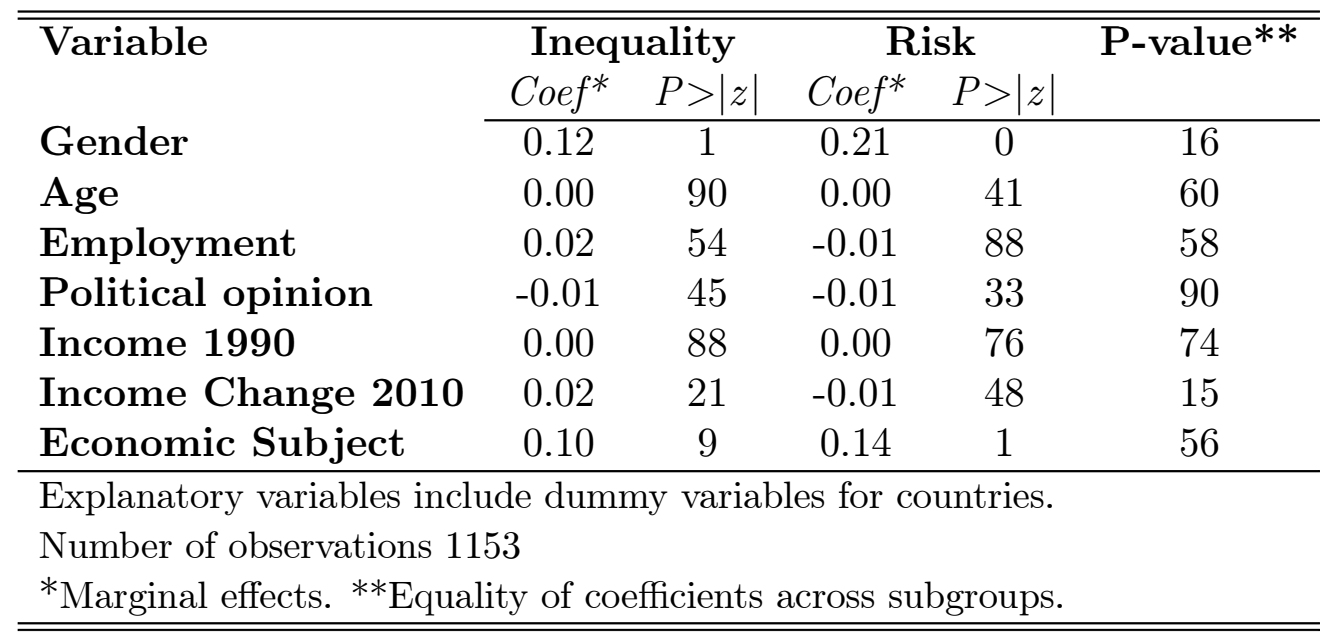

Table 6: Probit Regression of Consistency with Principle of Transfers

\begin{tabular}{|c|c|c|c|}
\hline & Total & Male & Female \\
\hline \multicolumn{4}{|c|}{ INEQUALITY } \\
\hline Question 1 & 40 & 44 & 34 \\
\hline Question 2 & 74 & 74 & 74 \\
\hline Question 3 & 61 & 62 & 60 \\
\hline Question 4 & 60 & 64 & 56 \\
\hline Question 5 & 72 & 70 & 76 \\
\hline Question 6 & 48 & 52 & 42 \\
\hline \multicolumn{4}{|l|}{ RISK } \\
\hline Question 1 & 49 & 55 & 39 \\
\hline Question 2 & 68 & 74 & 60 \\
\hline Question 3 & 59 & 66 & 52 \\
\hline Question 4 & 68 & 74 & 60 \\
\hline Question 5 & 67 & 71 & 60 \\
\hline Question 6 & 55 & 62 & 46 \\
\hline \multicolumn{4}{|c|}{ *Proportion of answer A. } \\
\hline
\end{tabular}

Table 7: Equalising Income Transfers Reduce Inequality/Risk?* 
There is more variation in the proportions of answer A for inequality than risk but the overall pattern is similar. Students are more likely to view an income transfer as inequality or risk reducing if it involves the richest region (Question 2 and Question 5), in particular if the recipient region is at the lower tail of the income distribution (Question 2). They are less likely to attribute an equalising impact to a transfer among regions, that are located near the middle of the income distribution and ranked next (Question 1) or in close proximity (Question 6) to each other.

The responses of female respondents vary more by question than those of male respondents. Apart from Question 5 for inequality, male students are more likely to choose A. Across questions, the differences between male and female proportionate responses are uniformly larger for risk than inequality.

\subsection{Regression Analysis}

One might wonder whether the clear differences in response patterns across questions carry through to the regression analysis. To address this, table 8 shows the result of re-running the probit regression from Table 5, adding fixed effects for each question. ${ }^{6}$ It is clear that the results from the descriptive analysis are indeed confirmed. All question dummy variables are negative, indicating a lower proportion of A responses relative to Question 2 (the "Pigou" case where the transfer is from the richest to the poorest region) . Question 5 (where the transfer involves the richest) has the highest coefficient, while Question 1 and Question 6 (where the transfer is among middle-ranking regions in close proximity) have the lowest coefficients.

Table 9 estimates probit regressions for each question separately. The results are by now familiar. First, responses for both inequality and risk vary typically only by gender and economic subject, while other personal characteristics remain generally insignificant. Second, the coefficients on gender and economic subject are (with one exception for gender) positive, indicating a higher probability of response A. Third, the coefficients on these two variables tend to be higher for risk than inequality (except for question 6), even though the differences are typically not significant.

\footnotetext{
${ }^{6}$ Question 2 was the omitted category.
} 


\begin{tabular}{lcccc}
\hline \hline Variable & \multicolumn{2}{c}{ Inequality } & \multicolumn{2}{c}{ Risk } \\
& Coef & $P>|z|$ & Coef & $P>|z|$ \\
\cline { 2 - 5 } Gender & 0.04 & 3 & 0.13 & 0 \\
Age & 0.00 & 85 & 0.00 & 36 \\
Employment & 0.03 & 10 & 0.00 & 99 \\
Political opinion & 0.00 & 75 & 0.00 & 93 \\
Income 1990 & 0.00 & 82 & -0.01 & 55 \\
Income Change 2010 & 0.00 & 78 & 0.00 & 92 \\
Economic Subject & 0.12 & 0 & 0.15 & 0 \\
Question 1 & -0.33 & 0 & -0.19 & 0 \\
Question 3 & -0.13 & 0 & -0.09 & 0 \\
Question 4 & -0.14 & 0 & 0.00 & 93 \\
Question 5 & -0.01 & 68 & -0.02 & 60 \\
Question 6 & -0.27 & 0 & -0.13 & 0 \\
\hline Number of observations & 3522 & \multicolumn{3}{c}{3396} \\
*Explanatory variables include dummy variables for countries. \\
\hline \hline
\end{tabular}

Table 8: Probit Regression of Response A with Question Dummy Variables

\begin{tabular}{|c|c|c|c|c|c|c|}
\hline & \multirow[t]{2}{*}{ Variable } & \multicolumn{2}{|c|}{ Inequality } & \multicolumn{2}{|c|}{ "Risk } & \multirow[t]{2}{*}{ P-value* } \\
\hline & & Coef & $P>|z|$ & Coef & $P>|z|$ & \\
\hline \multirow[t]{7}{*}{ Question 1} & Gender & 0.13 & 1 & 0.16 & 0 & 68 \\
\hline & Age & -0.01 & 24 & -0.00 & 38 & 80 \\
\hline & Employment & 0.02 & 65 & 0.01 & 79 & 89 \\
\hline & Political opinion & -0.01 & 58 & 0.01 & 53 & 40 \\
\hline & Income 1990 & 0.01 & 61 & -0.01 & 50 & 38 \\
\hline & Income Change 2010 & 0.02 & 31 & 0.01 & 62 & 68 \\
\hline & Economic Subject & 0.11 & 8 & 0.15 & 2 & 69 \\
\hline \multicolumn{7}{|c|}{ Number of observations 1134} \\
\hline \multirow[t]{7}{*}{ Question 2} & Gender & 0.00 & 99 & 0.11 & 1 & 5 \\
\hline & Age & 0.00 & 29 & -0.00 & 32 & 11 \\
\hline & Employment & -0.03 & 56 & -0.04 & 31 & 78 \\
\hline & Political opinion & 0.01 & 71 & 0.00 & 97 & 77 \\
\hline & Income 1990 & 0.00 & 99 & 0.03 & 13 & 29 \\
\hline & Income Change 2010 & 0.01 & 73 & -0.00 & 97 & 82 \\
\hline & Economic Subject & 0.11 & 4 & 0.12 & 1 & 84 \\
\hline \multicolumn{7}{|c|}{ Number of observations 1126} \\
\hline \multirow[t]{7}{*}{ Question 3} & Gender & 0.05 & 31 & 0.13 & 0 & 17 \\
\hline & Age & 0.01 & 22 & 0.00 & 38 & 79 \\
\hline & Employment & -0.02 & 68 & -0.01 & 89 & 85 \\
\hline & Political opinion & -0.01 & 55 & -0.01 & 64 & 93 \\
\hline & Income 1990 & 0.00 & 94 & -0.01 & 58 & 74 \\
\hline & Income Change12010 & 0.01 & 66 & -0.02 & 30 & 30 \\
\hline & Economic Subject & 0.14 & 2 & 0.18 & 0 & 63 \\
\hline \multicolumn{7}{|c|}{ Number of observations 1130} \\
\hline
\end{tabular}

*Equality of coefficients across subgroups. 


\begin{tabular}{|c|c|c|c|c|c|c|}
\hline \multicolumn{2}{|l|}{ Variable } & \multicolumn{2}{|c|}{ Inequality } & \multicolumn{2}{|l|}{ Risk } & \multirow[t]{2}{*}{ P-value* } \\
\hline & & Coef & $P>|z|$ & Coef & $P>|z|$ & \\
\hline \multicolumn{7}{|l|}{ [...continued] } \\
\hline \multirow[t]{7}{*}{ Question 4} & Gender & 0.09 & 4 & 0.12 & 1 & 55 \\
\hline & Age & -0.00 & 92 & 0.00 & 99 & 93 \\
\hline & Employment & 0.00 & 100 & 0.02 & 71 & 79 \\
\hline & Political opinion & -0.00 & 100 & -0.01 & 67 & 75 \\
\hline & Income 1990 & 0.00 & 89 & -0.01 & 67 & 83 \\
\hline & Income Change 2010 & 0.02 & 40 & 0.01 & 70 & 73 \\
\hline & Economic Subject & 0.06 & 27 & 0.18 & 0 & 10 \\
\hline \multicolumn{7}{|c|}{ Number of observations 1124} \\
\hline \multirow[t]{7}{*}{ Question 5} & Gender & -0.07 & 12 & 0.09 & 4 & 1 \\
\hline & Age & 0.00 & 70 & -0.01 & 18 & 43 \\
\hline & Employment & 0.07 & 10 & 0.03 & 53 & 47 \\
\hline & Political opinion & -0.01 & 46 & -0.05 & 1 & 17 \\
\hline & Income 1990 & 0.00 & 92 & 0.03 & 13 & 32 \\
\hline & Income Change 2010 & -0.01 & 47 & -0.00 & 85 & 68 \\
\hline & Economic Subject & 0.06 & 31 & 0.14 & 0 & 21 \\
\hline \multicolumn{7}{|c|}{ Number of observations 1127.} \\
\hline \multirow[t]{7}{*}{ Question 6} & Gender & 0.08 & 8 & 0.15 & 0 & 31 \\
\hline & Age & 0.00 & 63 & 0.00 & 53 & 92 \\
\hline & Employment & 0.06 & 19 & 0.00 & 92 & 39 \\
\hline & Political opinion & -0.00 & 82 & 0.00 & 85 & 77 \\
\hline & Income 1990 & 0.01 & 74 & 0.02 & 44 & 76 \\
\hline & Income Change 2010 & 0.03 & 19 & 0.02 & 46 & 65 \\
\hline & Economic Subject & 0.14 & 3 & 0.10 & 10 & 59 \\
\hline
\end{tabular}

Table 9: Probit Regressions of Response A by Questions 


\subsection{A provisional evaluation}

It has been known for some time that support for the Principle of Transfers does not enjoy universal support (Amiel and Cowell 1992). However the results reported here yield a deeper insight in that, first, we allow for a broader interpretation of the transfer principle as well as the conventional version that is attributable to Dalton (1920) and that, second, we look at whether the corresponding issue corresponds with individuals ranking of distributions in terms of risk. There is clear support for the Pigou version of the transfer principle, but not for the Dalton refinement. Although the overall pattern of responses looks fairly similar in the cases of risk and inequality - see for example Table 4 and the left-hand column of Table 7 - the picture differs markedly when one breaks down the respondents by gender: then it is no longer possible to maintain that the pattern of inequality attitudes is essentially the same as the pattern of risk attitudes either among men or among women.

\section{The Verbal Question}

As explained in Section 2 the respondents were also asked to fill out a verbal question in part 2 of the questionnaire. The responses to this question can give further insights as to the respondents' conformity, or otherwise, with economic orthodoxy.

\subsection{The structure of the question}

First a brief description of the question itself:

- The story of Alfaland is extended by asking individuals to consider the effect of transferring income exogenously from a rich region to a poorer region.

- There are five possible responses, including "none of the above".

- Individuals are allowed to check more than one response.

- Only response "d" is consistent with the orthodox view.

Because the questionnaire is structured so that respondents come to the verbal question and its various explanations after completing the numerical questions we gave people the opportunity to indicate whether they would have wanted to change their responses on the numerical problems. 


\begin{tabular}{lcc}
\hline \hline & \multicolumn{1}{c}{ Inequality } & Risk \\
\cline { 2 - 3 } Equalising & Transfer Reduces & Inequality?* \\
Total & 28 & 28 \\
Male & 28 & 31 \\
Female & 28 & 23 \\
Consistency & with Transfer & Principle?** \\
Total & 23 & 24 \\
Male & 22 & 28 \\
Female & 24 & 19 \\
\hline$*$ Proportion of answers that include "d" \\
**Proportion of answers "d" only \\
\hline \hline
\end{tabular}

Table 10: Proportion of "d" responses on verbal question

\subsection{Verbal question: descriptive results}

The fact that respondents were allowed to make multiple selections from question 7 means that we can interpret consistency with economic orthodoxy in either a broad or narrow sense. On the narrow interpretation - whether for inequality or for risk - people should have checked "d" and nothing else. However, it might be reasonable to look at cases where, because of difficulties with understanding the question, or some perceived ambiguity, respondents checked both "d" and one or more other possibilities. These two interpretations correspond, respectively, to the lower and the upper halves of Table 10. We can see that, overall less than one quarter of respondents are consistent with economic orthodoxy on the narrow interpretation, and a little less than thirty percent for the broader interpretation; this applies to inequality or risk.

However, it is also evident that gender now plays an intriguing role. Recall that (from Table 4) women were more likely to answer $\mathrm{A}$ if in the first part of the questionnaire if the context of the problem were inequality rather than risk whereas the reverse was true for men. This pattern is exhibited again, but more strongly now so that, on the inequality interpretation, women's responses are more consistent with economic orthodoxy than those for men. In the case of risk we have a confirmation of the earlier result - men's responses are more in line with orthodoxy than women; but in this case the effect is even stronger in that men are now 50 percent more likely to give a "d" response than women. Finally note that the number of respondents in line with economic orthodoxy on both the numerical part and the verbal part is quite small: the proportion of responses with straight A's on questions 1-6 and "d" on question 7 is only 8 percent in the case of inequality and 10 percent 


\begin{tabular}{lcc}
\hline \hline & Inequality & Risk \\
\cline { 2 - 3 } Proportion of answers that & include "b" \\
Total & 41 & 37 \\
Male & 43 & 38 \\
Female & 38 & 36 \\
Proportion of answers "b" & only \\
Total & 31 & 28 \\
Male & 32 & 28 \\
Female & 30 & 28 \\
\hline \hline
\end{tabular}

Table 11: Proportion of "b" responses on verbal question

for risk.

Given that support for the Daltonian transfer principle was rather low, it is interesting to look at the responses on other views in the verbal question. The strongest support for each of the five responses offered on question 7 was for "b", the case where transfers from/to the extremes is considered to reduce unambiguously inequality or risk, but other transfers are not necessarily considered. If we focus on this response the results areas in Table 11. The significance of this is that support for the original Pigou interpretation of the transfer principle (covering both responses " $\mathrm{b}$ " and " $\mathrm{d}$ ") is quite high.

Finally note that the proportion of those who indicated that they wanted to change their responses to each of the numerical questions in the light of their answer on the verbal question was only about 1 to 2 percent on each of questions 1-6.

\subsection{Regression analysis}

Let us look once again at the role of personal factors on the response to the verbal question using probit regressions. Table 12 deals with responses that are either "d" or "d combined with something else". Table 13 deals with the more restrictive interpretation: here we consider responses " $d$ and only $d$ " against alternatives. Economic subject continues to be significant for the risk subsample on either the broad or narrow interpretation. Political opinion is also important, but again, only for risk: the more you are self-reportedly left-wing the greater is your probability of responding in line with economic orthodoxy. However Gender is only significant at the $10 \%$ level for the risk subsample - men are more likely to respond in an orthodox fashion. 


\begin{tabular}{|c|c|c|c|c|c|}
\hline \multirow[t]{2}{*}{ Variable } & \multicolumn{2}{|c|}{ Inequality } & \multicolumn{2}{|c|}{ Risk } & \multirow[t]{2}{*}{ P-value** } \\
\hline & Coef* & $P>|z|$ & Coef* & $P>|z|$ & \\
\hline Gender & 0.00 & 92 & 0.06 & 15 & 33 \\
\hline Age & 0.01 & 12 & -0.00 & 26 & 4 \\
\hline Employment & -0.04 & 34 & -0.01 & 76 & 64 \\
\hline Political opinion & -0.01 & 66 & -0.05 & 0 & 6 \\
\hline Income 1990 & 0.00 & 83 & 0.02 & 32 & 57 \\
\hline Income Change 2010 & 0.01 & 42 & 0.03 & 6 & 5 \\
\hline Economic Subject & 0.01 & 89 & 19 & 0 & 3 \\
\hline $\begin{array}{l}\text { Explanatory variables incl } \\
\text { Number of observations } 1 \\
{ }^{*} \text { Marginal effects. }{ }^{* *} \text { Equa }\end{array}$ & $\begin{array}{l}\text { de dum } \\
3\end{array}$ & ty varia & es for $\mathrm{cc}$ & untries. & \\
\hline
\end{tabular}

Table 12: Probit Regression of Response "d"

\begin{tabular}{|c|c|c|c|c|c|}
\hline \multirow[t]{2}{*}{ Variable } & \multicolumn{2}{|c|}{ Inequality } & \multicolumn{2}{|c|}{ Risk } & \multirow[t]{2}{*}{ P-value** } \\
\hline & Coef* & $P>|z|$ & Coef* & $P>|z|$ & \\
\hline Gender & -0.02 & 56 & 0.07 & 9 & 10 \\
\hline Age & 0.01 & 1 & -0.00 & 38 & 1 \\
\hline Employment & -0.05 & 18 & -0.02 & 69 & 49 \\
\hline Political opinion & -0.01 & 73 & -0.03 & 3 & 16 \\
\hline Income 1990 & 0.00 & 94 & 0.01 & 49 & 57 \\
\hline Income Change 2010 & -0.02 & 23 & 0.04 & 4 & 4 \\
\hline Economic Subject & 0.01 & 81 & 0.18 & 0 & 4 \\
\hline
\end{tabular}

Table 13: Probit Regression of Consistency with Principle of Transfers 


\section{Conclusions}

Our focus has been on a fundamental question of the way in which people make distributional comparisons in the context of inequality and risk whether they do so in a manner that is consistent with model that is conventionally constructed in theoretical and applied economics, and whether the same structure of comparisons is used both for inequality and for risk. Focusing on these issues raises the question of what determines attitudes towards risk and inequality: we might reasonably expect personal characteristics, like gender, income, and subject of university degree, to play a role.

The main finding is that for numerical questions gender matters for attitudes towards risk and inequality, particularly for ranking judgments based on numerical comparisons. based on the evidence in Sections 4 and 5 female students are less likely than male students to view an income transfer from a rich to a poor person as risk- or inequality-reducing. In particular we have .

1. The difference in male and female responses is particularly large for risk.

2. According to the descriptive analysis, more male than female students attribute an inequality or risk reducing impact to an equalising income transfer. The difference is larger for risk than inequality. This pattern applies both for all responses jointly and for each question separately. Male respondents are also more consistent with the Principle of Transfers and, again, the difference is larger for risk than inequality.

3. The regression analysis shows that gender remains important once we control for other personal characteristics. The gender dummy is significant, and larger for risk than for inequality. The same applies for economic subject. These results apply regardless of whether we look at the responses jointly, separately by question, or with regard to consistency with the Principle of Transfers.

4. Respondents are most likely to view an income transfer that occurs from upper to the lower end of the income distribution as inequality/risk reducing. They are less likely to attribute an equalising effect when the transfer occurs 'within' the income distribution amongst regions ranked in close proximity to each other. The type of income transfer matters more for inequality than risk, and more for female than male students. 


\section{References}

Amiel, Y. and F. A. Cowell (1992). Measurement of income inequality: Experimental test by questionnaire. Journal of Public Economics 47, $3-26$.

Amiel, Y. and F. A. Cowell (1999a). Income transformations and income inequality. In D. Slottje (Ed.), Advances in Econometrics, Income Distribution and Scientific Methodology, pp. 209-232. Heidelberg: Physica Verlag.

Amiel, Y. and F. A. Cowell (1999b). Thinking about Inequality. Cambridge: Cambridge University Press.

Amiel, Y. and F. A. Cowell (2000). Risk and inequality perceptions. Distributional Analysis Discussion Paper 55, STICERD, London School of Economics, London WC2A 2AE.

Amiel, Y., F. A. Cowell, and A. Polovin (2000). Risk perceptions, income transformations and inequality. Working paper, STICERD, London School of Economics, London WC2A 2AE.

Dalton, H. (1920). Measurement of the inequality of incomes. Economic Journal 30(9), 348-361.

Kroll, Y. and L. Davidovitz (1999). Choices in egalitarian distribution: Inequality aversion versus risk aversion. Distributional Analysis Research Programme Discussion Paper 43, STICERD, LSE, Houghton Street, London WC2A 2AE. 


\section{A Appendix}

\section{A.1 Variable definitions}

Respondents were asked about seven background variables and, in addition, we had information about the particular subsample in which they were included from the location of the experiment. Of the seven two were binary "Are you male or female?", "Were you employed before University?" - and one was numerical - "What is your age?"; these are all self-explanatory.

Viewpoint questions were based on a seven-point scale as depicted at the end of each questionnaire in Appendix A.2.

Individuals wrote their own unguided response to "What is your special subject of study?" unless they were in a class where the subject was homogenous. Given that the study of economics could be argued to play a role in shaping individuals' attitudes in these areas we chose two possible definitions of the concept:

"Core Economics" subject categories:

economics

econometrics

economic history

mathematical economics

"Broader Economics" subject categories:

Core economics plus

Accounting $\&$ finance

Business

Management science

$M B A$

"Non-Economic" subject categories:

Behavioural science;

Engineering;

Government/politics;

Geography;

History;

International relations;

Law;

Philosophy;

Operational research. 


\section{A.2 The Questionnaires}

Following are the two questionnaires that were distributed to each of the response groups. As explained in the text the experiment was run so that each respondent had approximately an equal probability of receiving either of the two questionnaires. 